\title{
AC 2008-2253: FOLLOWING UP ON ENGINEERS OF THE FUTURE (EOF) WORKSHOP MOMENTUM
}

\section{Stephanie Goldberg, Buffalo State College}

Stephanie Goldberg worked as a test engineer for 10 years prior to joining Buffalo State College's Engineering Technology faculty. Courses taught include Digital Electronics, Microcontrollers, Analog Circuits, DC and AC Electrical Circuits.

\section{Paul Siciliano, Buffalo State College}

Paul Siciliano's expertise is in multidisciplinary studies focusing on Art, Design and Technology. His teaching includes work with learners of all ages and ability levels, with certifications in elementary, special, industrial arts, and gifted education. He has taught psychology, special education, art, materials, science, motivational theory, curriculum development and related higher education subject matter. He helped found and teaches at a summer camp for gifted children and has a sculpture studio in West Virginia.

\section{Clark Greene, Buffalo State College}

Mr. Greene has 20 years of experience in classroom instruction, curriculum writing, delivering professional development and leading standards writing initiatives for technology education

\section{Steve Macho, Buffalo State College}

Dr Steve Macho, a Minnesota farm boy has been involved in technology his entire life. Steve participated in an early concurrent program studying robotics technology in 1984. In the 1980s Steve worked in a variety of industrial and production facilities applying "hi-tech" solutions to automate and increase productivity. Steve worked Los Alamos National Laboratory in the Science Education Group (LANL/SEO) and at New Mexico Highlands University (NMHU). Steve is a Microsoft Certified Professional Internet Engineer (MCP+I), Microsoft Certified System Engineer (MCSE), Microsoft Certified Trainer (MCT), and is the author of "The Impact of Home Internet Access on Test Scores." Currently, Dr Macho is an Assistant Professor of Technology Education for the State University of New York (SUNY) at Buffalo State College. 


\section{Following up on Engineers of the Future (EoF) Workshop Momentum}

\section{Introduction}

Buffalo State College's Technology Education faculty and Engineering Technology faculty were brought together this summer through a New York State Engineers of the Future (EoF) grant awarded to the Technology Education program. The summer event gathered over 200 New York middle and high school and middle school technology instructors at Buffalo State College (BSC) to participate in teacher-training workshops incorporating United Kingdom (UK) engineering education strategies. Workshop participants were immersed a design and engineering curricula, based on the UK "Design and Make" pedagogy, which coordinates and fortifies students' technology and design experience at early points in their education. As faculty members of the Technology Education and the Electrical Engineering Technology programs, we were extremely impressed by both the level of sophistication and the accessibility of the workshop activities. We remain excited by the possibilities and potential of our incoming students participating in these wonderful activities, preparing them for their technical college experiences at institutions such as BSC.

The workshops offered through the EoF grant featured 3D Solid Modeling, Biotechnology, Product Design Engineering, and Digital Electronics and Control Systems. Our paper will focus on the Digital Electronics and Controls System workshop (DECS) which was held in BSC's Engineering Technology Analog and Digital Circuits Laboratory. The DECS course was developed and presented by UK design and instruction system experts. The aim was to support in-service teachers with the incorporation of digital electronics activities in their classrooms. The recent availability of programmable systems providing low cost "computers on a chip" served as the key process block in the students' coursework structure. Students can make design decisions and test the ideas on a computer in a classroom setting prior to prototyping a working model.

The students' decision-making process of product design is not isolated within an electromechanical universe, however. The design-based instruction allows students to integrate electronics and mechanical means while addressing issues of social and environmental concern related to the impacts of technology. Math, science and other interrelated curricular areas are addressed through the problem solving product design process, resulting in sound multidisciplinary instruction while engaging student interest.

The EoF program strategy was to bring the UK expertise to the workshop participants. We will examine the impetus and trajectory of the UK Design and Technology pedagogy and how this pedagogical structure is relevant in our students' general education experiences. In addition to providing an overview of the unique experience of the EoF summer program and DECS lab exercises, our paper will examine issues encountered by DECS participants as they attempted to integrate these activities. We will address comfort levels and cost issues of participants as they incorporated these technical exercises within their schools. Survey results will be provided in order to highlight the impact and popularity of the overall EoF experience. A summary of 
feedback gathered during post-workshop visits by Buffalo State faculty to participating EOF schools will be presented. We will also discuss follow up issues raised by DECS participants based upon informal post-workshop communication. We are eager to build on these inspiring summer sessions to continue extensive, meaningful connections with middle and high school technology teachers across New York State and beyond. This should allow us to both recruit and better-prepare Buffalo State College's future Engineering Technology and Technology Education students.

\section{Engineers of the Future (EoF) Project}

High school and middle school technology teachers across New York State attended workshops that provided curricular content and activities to enable engineering relevant learning in middle school and high school classrooms at a low to moderate cost. Internationally recognized education leaders and industry representatives in concert with Buffalo State College technology education and engineering technology faculty collaborated to design and deliver the workshop programs. ${ }^{1}$

The goal of EoF was to serve geographic areas of New York State that are precluded from using expensive, commercially-based engineering education programs. The data indicated that the vast majority of participants were technology teachers in the high school and middle-school range. Over 200 teachers participated in workshops, with 17 and 21 respectively attending the 2 sections of the DECS. Over half of the participants held masters degrees. An extrapolation of survey results over the whole spectrum of workshops suggests that about 28,000 students will receive some component of engineering education as a result of the EOF workshops. ${ }^{1}$ Some teachers are modifying their instruction to include design elements. Others are adding components of the workshops to their existing curricula, and a few have the flexibility to adopt selected curricula in their entirety.

Affordability was a major consideration of experiment selections for the workshops. In-service teachers are often subject to severe budget constraints. Cost effectiveness was a main feature of the overall workshop experience. The EoF summer sessions were provided at no cost to Technical Instructors of their school districts; participation by school districts was therefore not limited by tuition. In addition, participants had a choice of a $\$ 1000$ stipend, or graduate credit.

The UK approach to electronics is intended to capture the enthusiasm and design creativity of middle and high school students, without the need for detailed technical understanding. (The activities could be modified for elementary age learners, but the workshops did not address that age level.) The methods employed to achieve success without sophisticated technical knowledge were the use of a systems-based design and early-on integration of programmable systems (PIC microcontrollers modified for ease of programming). ${ }^{2}$ Most of the equipment for the DECS workshop experiments can be purchased in both the UK and the US.

Four experiment activities in the DECS workshop, which are detailed in a later section, bring engineering design experience at an understandable level, at low-cost, to middle and high schools learners and educators. Participation in the experiments was supplemented by lectures and discussions of best practices for in-class implementation. As part of the grant, participants 
were given laboratory equipment and software for use in their classrooms, providing continuity and motivation to implement these activities in their schools.

DECS workshop participants were also given a memory stick containing curricular materials and support documentation for the lab experiments. They were encouraged to register on the Electronics in Schools Strategy (EISS) website ${ }^{3}$. This website provides teachers with access to a dedicated training resource and in-depth support material, designed to help promote, teach and support Electronics, Communications and Technology (ECT) within school curricula.

\section{Pedagogy}

Workshops were developed and run by recognized leaders in their respective disciplines. The DECS workshop was presented by UK personnel, where, for decades, education has embraced design as a pedagogical foundation. Technology Education in the US has long recognized design as a critical element of instructional strategy, but this has not translated from academic musings to standard practice in the field. Paul W. DeVore, one of the seminal thinkers in the development of Technology Education, stated in $1987^{4}$ :

Design is an element that was overlooked early in the evolution of the discipline but is now recognized as quite central to the field. Closely related to design, creativity, invention and innovation are valuing and assessing components. These elements are central to guiding the continual corrections and adjustments required to attain the desired long-term goals whether they relate to shelter, energy, food and clothing or to the large scale infrastructures and systems associated with communicating, producing or transporting.

The focus of the design theme of the new technology on "design with nature" and the GAIA hypothesis directs attention to the evolving sub-discipline of biotechnology. The emerging biotechnologies hold high promise for the creation of a long-term sustainable and preferable human future.

The architects of the EoF Program recognize the essential importance of design as the central pedagogical structure for the study of the discipline of technology. A primary aim of EoF is the widespread adoption of design as the focus of instruction in the technologies. This goal, long recognized by technology educators in the United States, has been realized in the UK.

During the 1960s there were growing 'grass roots' concerns in the UK that technology education focused predominantly on manual construction skills and neglected higher order thinking skills. To address this concern a series of government-supported studies, pilot projects and reports led to a paradigm shift in UK technology education. The emphasis went from the training sphere to a focus on design as a process involving critical thinking skills such as evaluation, ideas generation and synthesis, as well as manual and manufacturing skills. This educational evolution lead to the Parkes Report ${ }^{5}$ which laid the foundations for design and technology as a compulsory area of study for all students, from the age of 5 to 14 in the English National Curriculum.

The merging of Design and Technology (D\&T) is based on each discipline's uniqueness as well as the sense that together, and only together, they can provide students with the (... capability to 
operate effectively and creatively in the made world. ${ }^{5}$ ) One of the special qualities of D\&T as noted in the report is: . . . always purposeful, i.e. developed in response to perceived needs or opportunities, as opposed to being undertaken for its own sake), takes place within a context of specific constraints (e.g., deadlines, cash limits, ergonomic and environmental requirements as opposed to unconstrained, blue-sky research) and depends upon value judgments at almost every stage. 5

Dave Barlex, who authors the lead chapter 'Justifying Design \&Technology', in a new book called Design and Technology for the Next Generation summarizes the development of D\&T in the National Curriculum following the 1988 report. He presents a 2007 draft of an "Importance a Design and Technology Statement".

In design and technology pupils combine practical and technological skills with creative thinking to design and make products and systems to meet human needs. In design and technology pupils learn to use today's technologies and participate in developing tomorrow's. They learn to think creatively and intervene to improve quality of life, solving problems as individuals and members of a team. Working in stimulating contexts that provide a spectrum of opportunities and draw on the local ethos, community and wider world, pupils identify needs and opportunities. They respond with ideas, products and systems, challenging expectations where appropriate. They combine practical and intellectual skills with an understanding of aesthetic, technical, cultural, health, social, emotional, economic, industrial and environmental issues. As they do so, they evaluate present and past design and technology, and its uses and effects. Through design and technology pupils become confident practically and develop as discriminating users of products. They apply their creative thinking and learn to innovate, developing their self-esteem.

Barlex points out that the statement enhances the 1988 report's emphasis for students to operate effectively and creatively in the made world. He notes the additional and still open concern that although D\&T has successfully evolved based on the report, it does not adequately engage student concerns with the effects of technology on their lives and the lives of others. Barlex references the work of Margarita Pavlova ${ }^{7}$ who proposed incorporation of socially relevant lab experiments that accomplish the technical requirements of the curriculum, while integrating topical societal issues relevant to student. Successful design solutions would, by necessity, be multidisciplinary. The DECS workshop experiment, USB Torch Design, exemplifies Pavlova's philosophy. In this activity a supercapacitor is charged via USB ports. It is based on "Electronics (Almost) Without Batteries", one of the experiments in the Tools for Change, Education for Sustainability article collection. ${ }^{8}$

\section{Lab Exercises in the Digital Electronics and Controls Workshop}

The Digital and Controls Workshop ran for nine days and included carefully chosen lab exercises that began with modular system-level design experiences to printed circuit board fabrication to the programming and design of a robot control circuit. The main 4 lab areas were:

- PIC Sounds and PICAXE School Experimenter Board - intro to concepts

- Control Studio - insight into application types, learn subcomponents

- USB torch - PCB manufacture, battery-less

- Gears - programming, robotics including pneumatics and industrial-strength components 
Each experiment is described below. The feasibility of participants performing the experiments in their classes is discussed. UK and US suppliers of kits and associated parts can be found in the appendices.

Systems-based laboratory design exercises using friendly, easily programmed devices makes engineering design concepts realizable to young students. A systems-based design approach for students takes a point of view that sees electronic systems in block diagram terms, and in which design choices are made about input sensor, electronic processing, and output device subsystems first, without having to deal with voltage levels, current loading, etc. Today's CAD and simulation software for electronics enhance a system's approach, which can be introduced to students as early as the start of middle school.

Systems theory is a central tenant of Technology Education. A simple systems model assists students in gaining an understanding of complex technologies. The concept of an interrelated relationship of inputs, processes, outputs and feedback loops is introduced as integral to all technical systems. The workshop structure incorporating this rationale was easily assimilated by the teachers because it mirrored practices already existing in their classrooms. Students will have hands-on reinforcement of one of the primary pedagogical constructs of technology education through the implementation of these experiments and design problems.

The in-service teachers adopted a role as students in the systems-based laboratory design structure. They were introduced to PICs at the start of the workshop, interspersing systems ideas and working towards full circuit design at a later stage. This was an extension of an approach that has been used successfully with British teachers (generally on 4-day workshops) with backgrounds in electronics ranging from virtually zero to graduate level electronics experience. ${ }^{2}$

\section{A PICsounds and PICAXE School Experimenter Board}

The PICsounds and PICAXE School Experimenter Board experiments can bring a meaningful introduction to students in both middle school and high school. As discussed below, teachers can quickly gain the expertise required to comfortably deliver this experience to their students.

PICsounds and the PICAXE School Experimenter Board are two kits designed as a flexible introduction to systems, control, and microcontrollers for students of middle-school and high-school age. Each kit includes a prefabricated circuit board along with a handful of components to be soldered on including an 8-pin PICAXE microcontroller IC. For example, the Experimenter board (see Fig. 1) has three different

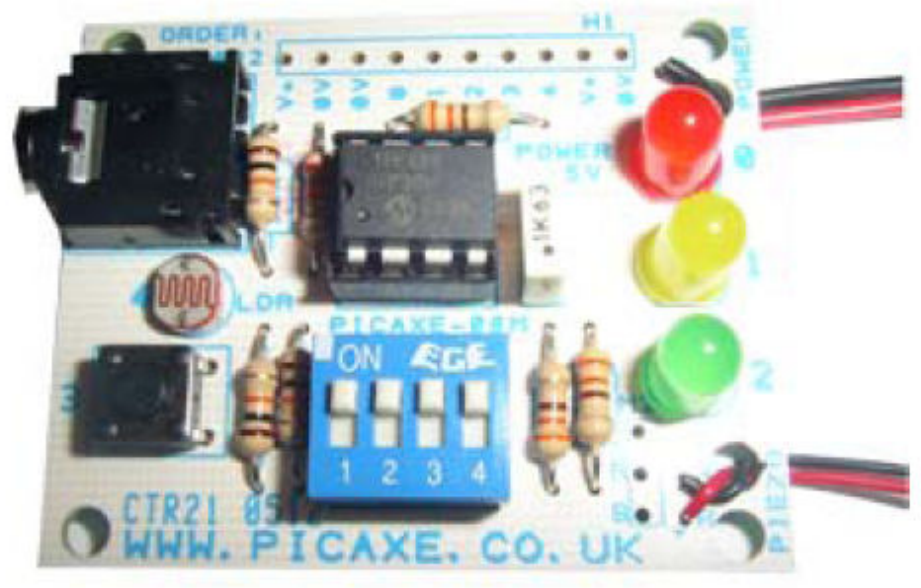

Figure 1 PICAXE School Experimenter Board 
color LEDs as outputs, and a manual switch and LDR sensor for inputs, and the PICAXE microcontroller for making decisions.

The PICAXE chip, a modified PIC microcontroller, allows students to easily program the chip via a serial or USB cable while it is in the kit circuit board. Students were exposed to two PC based software applications for development and testing of PICAXE programs. The PICAXE Programming Editor and the PIC Logicator provided a studentfriendly programming environment for PICAXE chips. These PC-based tools permit students to employ click and drag system modules in their design (see Fig. 2).

The kits provide an introduction to product design and manufacturing, echoing the Design and Make pedagogy, and give students hands-on experience handling components, assembling them on a circuit board,

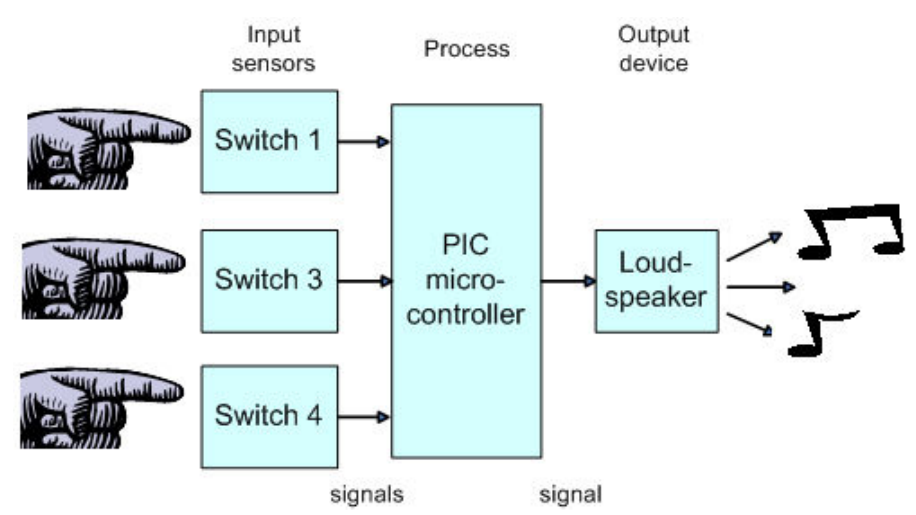

Figure 3 System Diagram and testing

them. Later

workshop

exercises progressed with electronic

circuit design and printed circuit board fabrication.

The systems-level approach is so keenly demonstrated in these early workshop experiments. For the PICsounds kit there are 3 input switches and one loudspeaker output. Students design their experiment using a systems block diagram such as Fig. 3, and do not have to be involved with interfacing issues such as voltage level compatibility and current loading. When designing their code, students click and drag on "systems-level actions" such as "Turn on Red LED" or "Is Switch 2 on". The PIC Logicator software application allows students to customize the captions in each flow chart block.

There is an excellent troubleshooting procedure to accompany the installation of components on the Experimenter board. This portion of the experiment is structured to guide students through the process of troubleshooting. By installing the PICAXE chip first, the chip can be used as an on-board tester for the additional components. Students can proceed to install one additional component at a time and download and run a premade PICAXE program that verifies the functioning of the added component. The order of installation is important; for example, students will be guided to solder in the yellow LED and then download the YELLOW LED test. The experiment certainly gets students thinking about troubleshooting. Classroom experiments can involve student groups deciding what they'd like to happen with their system of inputs, outputs, and PICAXE decision block. When the Experimenter board is populated and verified, students can build a real product based on the pre-tested system. 
The PIXAXE School Experimenter Board and PICsounds kits highlight for students what the basic components of an embedded microcontroller system are: input information, decisionmaking based on input information, and output action. Students get to design and construct a simple example that reflects the building blocks of any embedded system. The software environment allows simulation of their preliminary ideas. Associated workshop lectures bolstered systems model concepts for the educators by identifying more complex input and output components such as high-power motors, with the use of an "interface block" preceding a high-powered output device to handle power concerns. Students were introduced to motors in the final GEARS experiment

The pedagogical structure of these design-based activities allows middle and high school instructors to effectively engage students intellectually and physically through prototyping, experimentation and fabrication. The experiments are carefully bounded: small, self-contained, well-documented enough, with cost effective replacement parts. The experiments incorporate a simple and well-documented board; instructors can easily master the exercises to detect faults and errors that their students will encounter. With brief practice, an in-service teacher can take confident charge of this exercise.

Workshop participants were given 20 PICsounds kits and a copy of the PICAXE Programming Editor to take back with them to their classrooms.

\section{B Control Studio}

Controls Studio is a software application. To get started, students can click on a simple problem description, such as "a caretaker needs to know when the baby is crying". Then the user must select a module from system groups of inputs, outputs, and processes. The user can even click on each module to obtain a "datasheet" for that module, of course much simplified. Fig. 4 showcases a participant's design which turns a fan, illuminates and LED, and sounds a buzzer when the temperature exceeds a certain reference. Once the student organizes their design, they can simulate it, which involves using the mouse to vary the sensor input. The outputs "buzz" and "spin" and "light up" in response.

Controls studio provides sophisticated applications of the possibilities of systemlevel design by building upon the simple problem-solving structure of PIC School Experimenter. There is a module selection for each system category, menus for each system-level block, sensors, decision block, output,

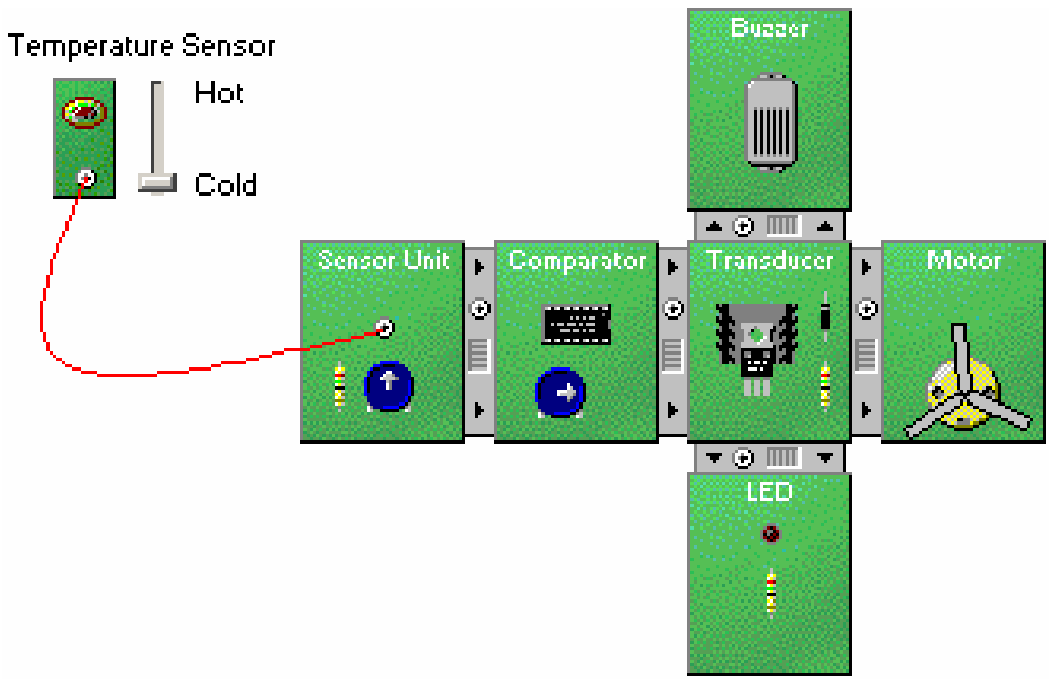

Figure 4 Control Studio Example and interface blocks. The student has to select a general interface block when taking signals 
from sensors or transmitting signals to an output such as a buzzer or LED. Exact calculation of resistance values, voltage requirements, circuit loading and capacities are not required for success. Students recognize, however, that an 'interface block' is essential, and is often required when coordinating systems. The flexibility of the design and problem structure provides the instructor with the ability to add calculations for learners who savor the challenge of mathematical manipulations.

Control Studio experiments are self-contained. Once an instructor has practiced with it they can facilitate the design and simulation of student experiments. An additional feature of Control Studio is the ability to automatically convert a design such as the one in Fig. 4 into a circuit schematic, which can then be exported to Circuit Wizard or a similar software application to fabricate a printed circuit board (PCB).

\section{USB Torch}

This four-component system allows a 1 Farad super-capacitor to be charged via a USB port and provide about a minute of illumination time to a bright blue LED.

The USB torch experiment requires a bit more from teachers in terms of experience and equipment. A method of PCB production is needed, which has associated cost and equipment requirements. A circuit board design program may be purchased, but students can also generate their own schematics using simple drawing programs already available on most PCs. If the administration will approve the expense, it seems well-worth going with Circuit Wizard software, a unique education product that allows introductory circuit designs to be generated and printed. There is an option to automatically create the artwork right from a circuit schematic.

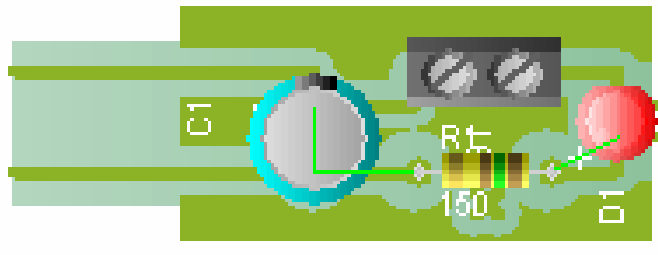

Figure 5 USB Torch

The USB Torch proves to be an engaging

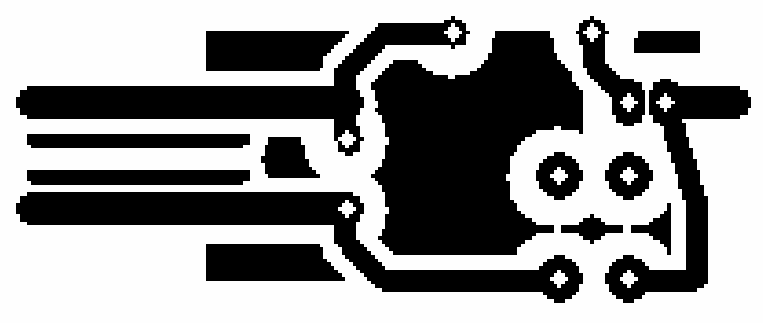

Figure 6 Artwork for USB Torch experiment and participants were able to take home an electronic system they had personally designed. Additionally, the USB torch presented an opportunity to understand how supercapacitors can support a no-battery, eco-friendly design. Students were faced with PCB problem-solving constraints such as providing paths for power and ground, which translated into IC design scenarios and solutions.

As noted, this experiment requires considerably more preparation, training and equipment needs in order for teachers to undertake this experiment with their classes. In order to fabricate the PCBs in class, the appropriate equipment will be needed. It is possible for students' circuit board designs to be fabricated commercially, but the costs may prove prohibitive. Some of the motivation for in-class PCB fabrication is based on reduced cost, but there is a sound pedagogical rationale for the UK "Design and Make" philosophy. When developing the 
workshop, it was noted that UK electronics teachers generally feel that it is a 'Good Thing' for pupils to see a PCB being produced at least once - so they recognize it is a straightforward process with no magic involved. One of the authors of this paper incorporated the USB experiment in the Engineering Technology DC Circuits class here at BSC after witnessing the positive impact to students as they produced their own circuit boards.

From a multidisciplinary perspective, the use of the circuit-board etching equipment need not be limited to the technology or engineering curriculum. Circuit-board schematics are referred to as 'artwork' in industry, and some would argue that the enlarged designs have an intrinsic beauty. From a general education perspective, however, the equipment to etch PCBs, as well as the drawing programs to produce the 'artwork', are easily adapted to Fine Arts applications within the school. The chemical etchant for the PCB is effective with nonferrous materials such as copper and brass and can be used with a resist to create etchings, jewelry, decorations and other items. Safe use requires only eye, hand and clothing protection with adequate ventilation. The sharing of the equipment by a number of programs within the school helps to justify the expense, which is not prohibitive.

\section{Gears Kit}

The GEARS-IDS Invention and Design System is literally a toolbox containing industrialstrength components, including industry grade pneumatics and gearhead motors, precision stainless steel and aluminum drive components, interfaces with programmable controllers or RC radios. The expense of the kit is due to the robust competition-quality of the components. The GEARS-IDS Invention and Design System gives teachers the Industrial Strength tools they need to create world class engineering and robotics challenges for their students in the comfort and convenience of their own classrooms. ${ }^{9}$

Participants were grouped into teams and given a GEARS base, a basic 4-wheel platform, preassembled by workshop instructors to save time (the pre-assembly was not a trivial task). Students were given a task (see Fig. 5) and were responsible for assembling a PICAXE highpowered circuit board along with sensors to the platform and for programming the PICAXE to complete the task. It was a wonderful project, the goal not so much being to complete it as to experience what is involved in getting a task like that completed. As in all the experiments, but especially here, participants were involved in teamwork.

\section{GEARS Robot Task}

- Follow the track all the way to the obstacle under automatic control

- Negotiate obstacle

- Travel 3' from the front end of the obstacle

- Stop

- Place, drop or throw payload to land within the 1' target boundary 


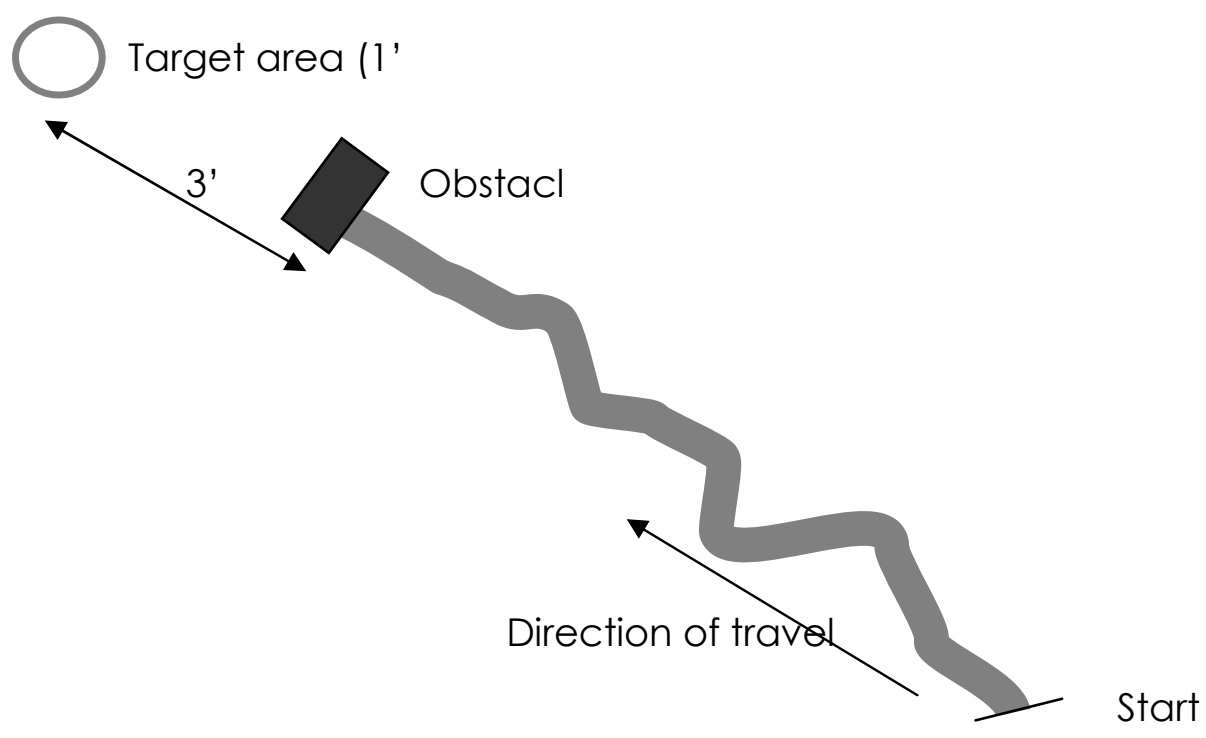

Figure 7 Robotics Challenge Track

One of the most useful aspects of this project was having a "hands-on mini-seminar" provided by GEARS personnel; the pneumatics portion of the mini-seminar was appreciated by all. The GEARS instructors are master teachers who incorporate high-level physics and mathematics within the training seminar. While extremely important and invaluable, this exercise would be an overwhelming task for most teachers without the personal training seminar. A school district that chose to undertake the expense of this equipment would surely see the value in properly trained staff to ensure effective instruction.

Gears experiment designs and outcomes are not known in advance, and involve high-power components, mechanics and pneumatics. This equipment would most appropriately be used in a capstone design and engineering course, with the possibility of a competitive component integral to the problem solving methodology. A school district may consider this equipment to be shared as part of a student club, overseen by teachers from participating school teams who are trained to provide students with guidance and oversight.

\section{EoF General Survey Results}

The data indicated that our participants were $87 \%$ technology teachers, $1 \%$ math teachers, $4 \%$ science teachers, and 8\% other types of teachers with 38\% high-school, 33\% mid-school, $14 \%$ high-school \& mid-school, $2 \% \mathrm{~K}-12$, and $13 \%$ other school (including: elementary, BOCES, and vocational). The level of experience of participating teachers was diverse, ranging from those just beginning their first year $(11 \%)$ to a maximum of 36 years teaching. The largest group was the $2^{\text {nd }}$ year teachers $(12 \%)$. Participants were most likely to have masters degrees (56\%), followed by bachelors (36\%), and the remaining $8 \%$ of other degrees ranged from those seeking certification to $\mathrm{PhDs}$.

Pre and Post general EOF surveys were given focusing on teachers' level of subject mater expertise. 209 participants completed the pre-test survey instrument, 204 completed the post- 
test. The teachers did believe that they gained subject matter expertise. Data has not yet been collected in a formal way to assess public school student learning based on the digital control workshop.

Qualitative Interview Results: In addition to the surveys, some participants were visited at their schools during the Fall 2007 semester. Based upon 34 qualitative interviews conducted with participants across the state during the fall 2007 school year, almost $60 \%$ indicate that they planned to use the new instructional methods emphasized within the EoFworkshops. Just over $30 \%$ indicated that they intended to undertake a complete restructuring of their curriculum to reflect the design and problem solving pedagogy of the EoF workshops. 50\% of the interviewees said they planned to incorporate the materials provided by EoF in their classroom instruction, with just over $40 \%$ asserting that they intended to undertake a complete restructuring of their course materials.

Post Survey Results: Approximately 64\% (just over 200 participants) completed the general EOF post-workshop survey. In the post survey, approximately 110 participants answered "most" or "all" to the question: "Did you work with scientists, mathematicians, or engineers during your training session?" Approximately 130 answered "mostly" or "all" to the question: "Do you plan to teach the subject matter presented here in your classes?" About 180 students answered "agree" or "strongly agree" to the question: "This course presented materials to support engineering-related career paths awareness."

190 students found the instructors to be "good" or better, with 180 students noting the materials were "good" or better. 94\% of the students noted they would participate in EOF courses again next summer if available and $96 \%$ said they would recommend EoF courses to colleagues. The content of the courses was found relevant and useful by $96 \%$.

Feedback from Instructors for future DECS workshops: Instructors noted that the participant group consisted of a wide variation in subject-matter expertise. It was suggested that future workshops be structured for beginner and advanced participants. It was also suggested that EoF provide participants with "refresher" opportunities.

In a situation where the coursework consists of numerous experiments and hands-on activities, covered in a short amount of time, more technical support for participants and instructors was requested. The availability of 'runners' to fetch 'emergency' parts, find orders, etc was also on the wish-list.

\section{Conclusion}

Informal post-workshop discussions with participants indicate a variety of comfort levels with the introductory PICsounds and PICAXE School Experimenter boards. While some feel comfortable leading these experiments in their classes, the majority expressed a desire for a follow up workshop to fortify their abilities. Many felt they could obtain funding for the introductory experiments with moderate effort. Most of the teachers noted comfort with the USB Torch experiment and felt that funding for it was also obtainable. Follow-up workshops and in-class technical support would be desired by most teachers in order to run experiments 
with the GEARS kit. Funding for the GEARS kits would be a major issue in most school districts. If the GEARS trainers could provide a demonstration at the school for students, parents, administrators and the School Board, some possible funding initiate could be launched.

Workshop participants left the workshops with documentation, curricular materials and a "goody-bags" of equipment and software, including 20 PICsounds kits and programming cables. They have a solid pedagogical foundation upon which to develop curriculum that includes hands-on design and problem-solving activities in their classes. There is general enthusiasm to participate in future EoF workshops, and a desire on the part of DECS workshop participants to engage in follow-up workshops to enhance mastery of the experiments.

The overall EoF survey results indicate excitement and motivation for the efforts and ongoing work of EoF. Teachers agree that they gained subject matter expertise and can enhance engineering-related career paths awareness. Additional survey questions reveal that more work is needed to increase middle and high school administrators' awareness of this curricular initiative. It is also critical that guidance counselors get on board.

\section{Appendix}

\section{A. Lead Instructors email:}

The lead instructors of the course look forward to future work with US schools.

John Martin: d.j.martin@ salford.ac.uk

Torben Steeg: torben@ steeg.co.uk

B. Electronics in Schools Strategy (EISS): http://www.electronicsinschools.org/

C. Experiment Kit and Software Suppliers (costs shown are approximate):

PIC Sounds and PICAXE School Experimenter Board

\begin{tabular}{|l|l|l|}
\hline Kits and Software & UK Supplier & US Supplier \\
\hline $\begin{array}{l}\text { PICAXE School Experimenter } \\
\text { Board }\end{array}$ & $\begin{array}{l}\text { Revolution } \\
\text { www.rev-ed.co.uk/picaxe/ }\end{array}$ & $\begin{array}{l}\text { HVW www.hwwtech.com } \\
\text { www.world-educational- } \\
\text { services.net }\end{array}$ \\
\hline $\begin{array}{l}\text { PICsounds } \\
\text { \$7 each }\end{array}$ & $\begin{array}{l}\text { Economatics } \\
\text { www.economatics-education.co.uk/ }\end{array}$ & www.fischertechnik.com \\
\hline $\begin{array}{l}\text { PIC Logicator - programming } \\
\text { for above kits (\$390 site } \\
\text { license) }\end{array}$ & $\begin{array}{l}\text { Economatics } \\
\text { www.economatics-education.co.uk/ }\end{array}$ & \\
\hline $\begin{array}{l}\text { PICAXE Programming editor - } \\
\text { programming for above kits } \\
\text { (free) }\end{array}$ & $\begin{array}{l}\text { Revolution } \\
\text { www.rev-ed.co.uk/picaxe }\end{array}$ & \\
\hline
\end{tabular}

\section{Control Studio}

\begin{tabular}{|l|l|l|}
\hline Kits and Software & UK Supplier & US Supplier \\
\hline $\begin{array}{l}\text { Control Studio Software } \\
\$ 1200 \text { for 25 seats }\end{array}$ & www.new-wave-concepts.com/ & Kelvin LP \\
www.kelvin.com \\
\hline
\end{tabular}


USB torch

\begin{tabular}{|l|l|l|}
\hline Kits and Software & UK Supplier & US Supplier \\
\hline $\begin{array}{l}\text { Components for USB } \\
\text { Torch }\end{array}$ & $\begin{array}{l}\text { Rapid } \\
\text { http://www.rapidonline.com/home.aspx }\end{array}$ & www.digikey.com \\
\hline $\begin{array}{l}\text { Printed Circuit Board } \\
\text { fabrication }\end{array}$ & & www.techniks.com \\
\hline $\begin{array}{l}\text { Circuit Wizard Software } \\
\$ 1200 \text { for 25 seats }\end{array}$ & www.new-wave-concepts.com/ & $\begin{array}{l}\text { Kelvin LP } \\
\text { www.kelvin.com }\end{array}$ \\
\hline
\end{tabular}

Gears Kit

\begin{tabular}{|l|l|l|}
\hline Kits and Software & UK Supplier & US Supplier \\
\hline $\begin{array}{l}\text { GEARS } \\
\$ 1200\end{array}$ & $\begin{array}{l}\text { Revolution } \\
\text { www.rev-ed.co.uk/picaxe }\end{array}$ & www.gearseds.com \\
\hline $\begin{array}{l}\text { PICAXE 18 Pin Power } \\
\text { Project Board \$12 }\end{array}$ & $\begin{array}{l}\text { Revolution } \\
\text { www.rev-ed.co.uk/picaxe }\end{array}$ & $\begin{array}{l}\text { Sparkfun } \\
\text { www.sparkfun.com }\end{array}$ \\
\hline $\begin{array}{l}\text { PICAXE 18 Pin } \\
\text { Microcontroller for above } \\
\$ 8\end{array}$ & $\begin{array}{l}\text { Revolution } \\
\text { www.rev-ed.co.uk/picaxe }\end{array}$ & $\begin{array}{l}\text { Sparkfun } \\
\text { www.sparkfun.com }\end{array}$ \\
\hline $\begin{array}{l}\text { PICAXE Serial } \\
\text { Programming Cable \$6 }\end{array}$ & $\begin{array}{l}\text { Revolution } \\
\text { www.rev-ed.co.uk/picaxe }\end{array}$ & $\begin{array}{l}\text { Sparkfun } \\
\text { www.sparkfun.com }\end{array}$ \\
\hline $\begin{array}{l}\text { PICAXE USB } \\
\text { Programming Cable \$24 } 4\end{array}$ & $\begin{array}{l}\text { Revolution } \\
\text { www.rev-ed.co.uk/picaxe }\end{array}$ & $\begin{array}{l}\text { Sparkfun } \\
\text { www.sparkfun.com }\end{array}$ \\
\hline
\end{tabular}

\section{Bibliography}

1. Final Engineers of the Future (EoF) Report (currently in process, will be delivered to the State Dept. of Education and available on request)

2. Digital Electronics and Control Workshop Report (available on request)

3. Electronics in Schools Strategy EISS website: http://www.electronicsinschools.org/

4. DeVore, P. W., 2030 A.D.: Critical Distance and Critical Paths to 2080 A.D., published manuscript (available on request.

5. Department for Education and Science and Welsh Office (1998). "National Curriculum Design and Technology Working Group Interim Report". London: HMSO.

6. Barlex, D., Justifying Design and Technology, (Chapter one of Design \& Technology for the Next Generation, Cliffe \& Company, Whitchurch, UK. (PDF of Chapter 1 available at http://bura.brunel.ac.uk/bitstream/2438/1649/1/D\&TNextGen_11Oct_02Barlex.pdf )

7. Pavlova, M. (2005). 'Social Change: How Should Technology Education Respond?'. 'International Journal of Technology and Design Education". 15, 199-215.

8. Tools for Change, http://www.secondarydandt.org/dt-world/reports/tools-for-change, 180,SA.html

9. GEARS-IDS Invention and Design System website: www.gearseds.com 